\title{
Effect of perioperative sodium bicarbonate administration on renal function following cardiac surgery for infective endocarditis: a randomized, placebo-controlled trial
}

\author{
Jin Sun Cho ${ }^{1}$, Sarah Soh ${ }^{1}$, Jae-Kwang Shim ${ }^{1,2}$, Sanghwa Kang ${ }^{3}$, Haegi Choi ${ }^{1}$ and Young-Lan Kwak ${ }^{1,2^{*}}$
}

\begin{abstract}
Background: Patients with infective endocarditis (IE) have an elevated risk of renal dysfunction because of extensive systemic inflammation and use of nephrotoxic antibiotics. In this randomized, placebo-controlled trial, we investigated whether perioperative sodium bicarbonate administration could attenuate postoperative renal dysfunction in patients with IE undergoing cardiac surgery.

Methods: Seventy patients randomly received sodium chloride $(n=35)$ or sodium bicarbonate $(n=35)$. Sodium bicarbonate was administered as a $0.5 \mathrm{mmol} / \mathrm{kg}$ loading dose for $1 \mathrm{~h} \mathrm{commencing} \mathrm{with} \mathrm{anesthetic} \mathrm{induction,}$ followed by a $0.15 \mathrm{mmol} / \mathrm{kg} / \mathrm{h}$ infusion for $23 \mathrm{~h}$. The primary outcome was peak serum creatinine (SCr) level during the first $48 \mathrm{~h}$ postoperatively. The incidence of acute kidney injury, SCr level, estimated glomerular filtration rate, and major morbidity endpoints were assessed postoperatively.

Results: The peak SCr during the first $48 \mathrm{~h}$ postoperatively (bicarbonate vs. control: $1.01(0.74,1.37) \mathrm{mg} / \mathrm{dl}$ vs. 0.88 $(0.76,1.27) \mathrm{mg} / \mathrm{dl}, P=0.474)$ and the incidence of acute kidney injury (bicarbonate vs. control: $29 \% \mathrm{vs} .23 \%, P=0$. 584) were similar in both groups. The postoperative increase in $\mathrm{SCr}$ above baseline was greater in the bicarbonate group than in the control group on postoperative day $2(0.21(0.07,0.33) \mathrm{mg} / \mathrm{dl} \mathrm{vs} .0 .06(0.00,0.23) \mathrm{mg} / \mathrm{dl}, P=0.028)$ and postoperative day $5(0.23(0.08,0.36) \mathrm{mg} / \mathrm{dl}$ vs. $0.06(0.00,0.23) \mathrm{mg} / \mathrm{dl}, P=0.017)$.

Conclusions: Perioperative sodium bicarbonate administration had no favorable impact on postoperative renal function and outcomes in patients with IE undergoing cardiac surgery. Instead, it was associated with possibly harmful renal effects, illustrated by a greater increase in SCr postoperatively, compared to control.
\end{abstract}

Trial registration: ClinicalTrials.gov, NCT01920126. Registered on 31 July 2013.

Keywords: Infective endocarditis, Cardiac surgery, Renal function, Sodium bicarbonate

\section{Background}

For the treatment of infective endocarditis (IE), recent evidence favors early surgical intervention to reduce the risk of stroke and death $[1,2]$. Surgery with cardiopulmonary bypass $(\mathrm{CPB})$, however, is inevitably accompanied by numerous factors that contribute to acute kidney

\footnotetext{
* Correspondence: ylkwak@yuhs.ac

1 Department of Anesthesiology and Pain Medicine, Yonsei Cardiovascular Hospital, Yonsei University College of Medicine, 50 Yonsei-ro, Seodaemun-gu, Seoul 120-752, Republic of Korea

${ }^{2}$ Anesthesia and Pain Research Institute, Yonsei University College of Medicine, Seoul, Republic of Korea

Full list of author information is available at the end of the article
}

injury (AKI) [3]. An early, exaggerated inflammatory response with oxidative stress and the preoperative use of nephrotoxic antibiotics further predispose patients with IE to renal impairment [4-6]. Indeed, AKI affects up to $60 \%$ of patients with IE undergoing cardiac surgery [6], and the occurrence and severity of AKI have been indisputably associated with mortality and poor outcomes [7].

Sodium bicarbonate has been demonstrated to protect the kidneys through urinary alkalization and increasing the tubular $\mathrm{pH}[8,9]$. It reduces the $\mathrm{pH}$-dependent conversion of hemoglobin to methemoglobin and production of free radicals via the Haber-Weiss reaction [10, 11]. 
After a pilot study reported that with sodium bicarbonate infusion there was a reduced incidence of AKI after cardiac surgery [8], numerous clinical trials evaluated its renoprotective efficacy in different types of surgery and patients, yielding conflicting results [12-15]. Considering the massive oxidative stress associated with systemic inflammation and prolonged use of nephrotoxic antibiotics in patients with IE [16], the abilities of sodium bicarbonate to attenuate oxidative stress may prove especially helpful in preventing AKI in these patients. However, most previous studies investigating the renal effects of sodium bicarbonate have excluded patients with systemic infection, and no study has heretofore been conducted solely in patients with IE. The aim of this prospective, randomized, placebo-controlled trial was to investigate the effect of perioperative sodium bicarbonate administration on postoperative renal function in patients with IE undergoing cardiac surgery with $\mathrm{CPB}$.

\section{Methods}

The study protocol was approved by the Institutional Review Board and Hospital Research Ethics Committee of Severance Hospital at Yonsei University College of Medicine (\#4-2013-0376) and registered at ClinicalTrials.gov on July 2013 (NCT01920126). The trial was conducted at Yonsei University College of Medicine in Seoul, Korea, between August 2013 and July 2016. After providing written informed consent, 70 patients between 20 and 80 years old, who were scheduled for valvular heart surgery for IE, were enrolled. IE was diagnosed according to the modified Duke criteria [17]. Patients were excluded if they met at least one of these criteria preoperatively: (1) estimated glomerular filtration rate (eGFR) $<15 \mathrm{ml} / \mathrm{min} /$ $1.73 \mathrm{~m}^{2}$; (2) receiving renal replacement therapy; (3) receiving intra-aortic balloon pump support; (4) preexisting hypernatremia, alkalosis, or severe pulmonary edema; or (5) chronic moderate dose to high dose corticosteroid therapy ( $>10 \mathrm{mg} /$ day prednisolone or equivalent).

Enrolled patients were randomly assigned to either the control or bicarbonate group at a 1:1 ratio using a computer-generated random-number table. Assignments were concealed in sealed envelopes. The study drugs were prepared in identical $50-\mathrm{ml}$ syringes by an anesthesia nurse not involved with the study. The bicarbonate group received $154 \mathrm{mEq} / \mathrm{l}$ sodium bicarbonate with a $0.5 \mathrm{mmol} / \mathrm{kg}$ intravenous (IV) loading dose over $1 \mathrm{~h}$ immediately after anesthetic induction, followed by an IV continuous infusion at $0.15 \mathrm{mmol} / \mathrm{kg} / \mathrm{h}$ over $23 \mathrm{~h}$. The control group received equivalent volumes of IV $0.9 \%$ sodium chloride for the same duration. Attending surgeons and anesthesiologists involved in patient management in the operating room and intensive care unit (ICU) were blinded to the group assignment. Group assignment was disclosed after hospital discharge.
All patients received institutionally standardized anesthetic care and CPB management as previously described [18]. Intraoperatively, all patients received balanced crystalloid (Plasma solution A 1000 inj, CJ, Seoul, Korea) at $6 \mathrm{ml} / \mathrm{kg} / \mathrm{h}$ and balanced synthetic colloid (Volulyte; Fresenius Kabi, Bad Homburg, Germany) to replace estimated blood loss (to a maximum of $500 \mathrm{ml}$ ). Mean arterial pressure (MAP) $<70 \mathrm{~mm} \mathrm{Hg}$ was treated with norepinephrine, with the infusion starting at $0.01 \mu \mathrm{g} /$ $\mathrm{kg} / \mathrm{min}$ and titrated to a maximum of $0.3 \mu \mathrm{g} / \mathrm{kg} / \mathrm{min}$. If the blood pressure was not maintained with norepinephrine, vasopressin was infused at 2.4-4.0 units/h. Milrinone $(0.5 \mu \mathrm{g} / \mathrm{kg} / \mathrm{min})$ was infused when the mixed venous oxygen saturation decreased below $60 \%$ for $>10$ minutes. Postoperatively, when urine output was $<1 \mathrm{ml} / \mathrm{kg} / \mathrm{h}$ for 30 minutes, loop diuretics were administered after a 200-ml IV bolus of crystalloid. If this was inadequate, fluid boluses were repeated up to three times. If urine output remained inadequate 15 minutes after the third bolus, $5 \mathrm{mg}$ of IV furosemide was administered and then repeated every 30 minutes, with escalating doses until the desired effect (urine output $>1 \mathrm{ml} / \mathrm{kg} / \mathrm{h}$ ) was achieved. Renal replacement therapy was initiated if any of the following occurred: refractory oliguria (urine output $<0.5 \mathrm{ml} / \mathrm{kg} / \mathrm{h}$ for $12 \mathrm{~h}$ ), fluid overload, hyperkalemia $(>6.5 \mathrm{mEq} / \mathrm{l})$, rapidly rising serum potassium level, signs of uremia, or metabolic acidosis $(\mathrm{pH}<7.10)$.

\section{Outcome measures}

The primary outcome measure was the difference in peak serum creatinine $(\mathrm{SCr})$ level between groups during the first $48 \mathrm{~h}$ postoperatively. We assumed that $>0.3 \mathrm{mg} / \mathrm{dl}$ difference in SCr would be clinically significant, based on the Acute Kidney Injury Network (AKIN) criteria [19]. Secondary outcomes included the incidence of postoperative AKI (diagnosed by the AKIN criteria) [19], electrolyte abnormalities, major morbidity endpoints, ICU and hospital length of stay, and in-hospital mortality. Changes in $\mathrm{SCr}$ and eGFR, which were measured before surgery, upon ICU arrival, and at least once per day until postoperative day (POD) 5, were assessed. Serum sodium $\left(\mathrm{Na}^{+}\right)$, potassium $\left(\mathrm{K}^{+}\right)$, bicarbonate, and $\mathrm{pH}$ were measured before surgery and at 6 and $24 \mathrm{~h}$ after commencing the study drug infusion. The incidence of hypernatremia (serum $\left(\mathrm{Na}^{+}\right)>150 \mathrm{mmol} / \mathrm{l}$ ), hypokalemia (serum $\left(\mathrm{K}^{+}\right)<3.5 \mathrm{mmol} / \mathrm{l}$ ), or alkalemia (serum $\mathrm{pH}>7.50$ ) was determined. The major morbidity endpoints were permanent stroke, hemostatic re-exploration, AKI, prolonged ventilator care $(>48 \mathrm{~h})$, and deep sternal wound infection.

Preoperative variables included demographics, preoperative morbidities, left ventricular ejection fraction, Cleveland Clinic score [20], and EuroSCORE. Factors associated with an increased risk of renal injury in patients 
with IE were investigated [6]. Intraoperative variables included the surgery duration, $\mathrm{CPB}$ and aortic crossclamp times, fluid balance, transfusion requirements, and vasoconstrictor/inotropic medication requirements. Hemodynamic variables, including heart rate (HR), MAP, mean pulmonary arterial pressure (MPAP), central venous pressure (CVP), and cardiac index (CI), were recorded 15 minutes after anesthetic induction, 15 minutes after weaning from $\mathrm{CPB}$, at sternum closure, upon ICU arrival, and at $24 \mathrm{~h}$ and $48 \mathrm{~h}$ after surgery. Postoperative variables included fluid balance, urine output, blood loss (chest tube drainage), packed erythrocyte transfusion, and vasoconstrictor/inotrope usage during the first $48 \mathrm{~h}$ after surgery. Body temperature, C-reactive protein level, white blood cell count, and percentage of neutrophils were measured before surgery and at least once per day until POD 5 .

\section{Statistical analysis}

The standard deviation (SD) of SCr level at $48 \mathrm{~h}$ postoperatively was previously reported as 0.4 in patients undergoing valvular heart surgery at our institute [18]. We estimated that 29 patients in each group would be required to detect a mean difference of 0.3 and SD of 0.4 in peak $\mathrm{SCr}$ levels during the first $48 \mathrm{~h}$ postoperatively, with $80 \%$ power at a significance level of $P<0.05$. Factoring in a $20 \%$ dropout rate, we enrolled 35 patients in each group.

Data are shown as mean $\pm \mathrm{SD}$, median (interquartile range), or number. Between-group comparisons of continuous variables were performed using the independent $t$ test or Mann-Whitney $U$ test, after testing for normality using the Kolmogorov-Smirnov test. Dichotomous variables were compared using chi-square test or Fisher's exact test. Serially measured variables were analyzed using a linear mixed model with patient indicator as a random effect and group, time, and group-by-time as fixed effects. This was followed by post hoc analysis using the Bonferroni correction. All statistical analyses were two-tailed and performed using SPSS 20 software (SPSSFW, SPSS Inc., IBM, Armonk, NY, USA). $P<0.05$ was considered statistically significant.

\section{Results}

Of the 70 patients enrolled, IE was definitively confirmed through surgical findings and pathologic examination in 32 patients in each group. According to the intention-to-treat principle, statistical analyses were performed using data from all enrolled patients. Four patients in each group $(P>0.999)$ underwent emergency surgery within $24 \mathrm{~h}$ after being diagnosed with IE. All patients were treated with antibiotics before the day of surgery. At the time of surgery, 29 (83\%) and 27 (77\%) patients in the bicarbonate and control groups, respectively, had active infection with a positive blood culture, leukocytosis $(>10,800 / \mu \mathrm{l})$, fever (temperature $>38{ }^{\circ} \mathrm{C}$ ), or elevated C-reactive protein $(>8 \mathrm{mg} / \mathrm{l})(P=0.550)$. The time between diagnosis of IE and surgery was similar in both groups (bicarbonate vs. control: $11(5,17)$ days vs. 8 (5, 17) days, $P=0.857)$. All baseline patient characteristics were comparable in the two groups, except that more patients received anti-platelet drugs prior to surgery (5 vs. $0, P=0.020$ ) and had platelet counts below 150,000 / $\mu \mathrm{l}(11$ vs. $3, P=0.017)$ in the control group (Table 1$)$.

\section{Renal outcomes}

The peak $\mathrm{SCr}$ level during the first $48 \mathrm{~h}$ postoperatively was not significantly different between groups (bicarbonate vs. control: $1.01(0.74,1.37) \mathrm{mg} / \mathrm{dl}$ vs. $0.88(0.76$, 1.27) $\mathrm{mg} / \mathrm{dl}, P=0.474)$. The postoperative increase in $\mathrm{SCr}$ above baseline was significantly greater in the bicarbonate group than in the control group on POD $2(0.21$ $(0.07,0.33) \mathrm{mg} / \mathrm{dl}$ vs. $0.06(0.00,0.23) \mathrm{mg} / \mathrm{dl}, P=0.028)$ and POD $5(0.23(0.08,0.36) \mathrm{mg} / \mathrm{dl}$ vs. $0.06(0.00,0.23)$ $\mathrm{mg} / \mathrm{dl}, P=0.017)$. Postoperative SCr levels were higher and eGFR values were lower in the bicarbonate group than in the control group, but the group $\times$ time interactions for the $\mathrm{SCr}$ level and eGFR during the five PODs were not statistically significant between groups in the linear mixedmodel analysis ( $P=0.055$ and 0.073 , respectively).

There were no differences in the incidence of AKI (bicarbonate vs. control: $29 \%$ vs. $23 \%, P=0.584$ ) or distribution of AKIN stages $(P=0.863)$ between groups (Table 2). No patient, except one who received renal replacement therapy in the control group, was oliguric $(<0.5 \mathrm{ml} / \mathrm{kg} / \mathrm{h})$ for more than $6 \mathrm{~h}$ and thus fulfilled the definition of AKI according to the urine output-based AKIN criteria. Of note, using another set of diagnostic criteria for AKI $[8,15,21]$ (increase in $\mathrm{SCr}>25 \%$ or $0.5 \mathrm{mg} / \mathrm{dl}$ from baseline), the incidence of AKI was significantly higher in the bicarbonate group than in the control group ( $60 \%$ vs. $31 \%, P=0.016)$.

\section{Fluid balance, vasopressor/inotrope requirements, electrolytes, and hemodynamics}

Intraoperative fluid balance, transfusion requirements, and use of vasoconstrictor/inotropic medications were similar in both groups, except that fewer patients received platelet transfusions in the bicarbonate group $(P=0.023)$ (Table 3). Changes in perioperative hemodynamic variables, including HR $(P=0.699)$, MAP $(P=0.950)$, MPAP $(P=0.361)$, CVP $(P=0.409)$, and CI $(P=0.939)$, were comparable in the two groups in the linear mixed-model analysis (see Additional file 1 for more detail).

Postoperative fluid balance, transfusion requirements, and use of vasoconstrictor/inotropic medications during the first $48 \mathrm{~h}$ after surgery were comparable in both groups, except that fewer patients received erythrocyte transfusions during the first $24 \mathrm{~h}$ after surgery in the 
Table 1 Demographic and perioperative clinical data

\begin{tabular}{|c|c|c|c|}
\hline & Control group $(n=35)$ & Bicarbonate group $(n=35)$ & $P$ value \\
\hline \multicolumn{4}{|l|}{ Demographics } \\
\hline Age (years) & $55.1 \pm 15.7$ & $53.9 \pm 14.1$ & 0.738 \\
\hline Sex (male:female) & $27: 8$ & $21: 14$ & 0.122 \\
\hline Body mass index $\left(\mathrm{kg} / \mathrm{m}^{2}\right)$ & $21.6 \pm 3.6$ & $22.0 \pm 3.3$ & 0.613 \\
\hline \multicolumn{4}{|l|}{ Cormobidities } \\
\hline Hypertension & 10 & 10 & $>0.999$ \\
\hline Diabetes mellitus & 6 & 4 & 0.495 \\
\hline Congestive heart failure & 1 & 0 & 0.314 \\
\hline Chronic kidney disease $(\mathrm{SCr}>1.4 \mathrm{mg} / \mathrm{dl})$ & 7 & 8 & 0.771 \\
\hline Ml within 1 month & 0 & 0 & \\
\hline Cerebrovascular disease & 5 & 3 & 0.452 \\
\hline COPD & 0 & 0 & \\
\hline Repeat surgery & 4 & 6 & 0.495 \\
\hline \multicolumn{4}{|l|}{ Preoperative condition } \\
\hline Left ventricular ejection fraction (\%) & $63.9 \pm 8.5$ & $65.9 \pm 7.4$ & 0.312 \\
\hline EurOSCORE & $4(2,9)$ & $5(3,8)$ & 0.449 \\
\hline Cleveland Clinic score $^{a}$ & $2(1,3)$ & $2(1,2)$ & 0.360 \\
\hline Vancomycin or aminoglycoside & 27 & 29 & 0.550 \\
\hline Contrast use $48 \mathrm{~h}$ prior to surgery & 19 & 14 & 0.231 \\
\hline Hemoglobin below $10 \mathrm{~g} / \mathrm{dl}$ & 14 & 8 & 0.122 \\
\hline Platelets below 100,000/ $\mu \mathrm{l} / 150,000 / \mu \mathrm{l}$ & 3/ 11 & $1 / 3$ & $0.303 / 0.017$ \\
\hline Embolic events & 8 & 13 & 0.192 \\
\hline Prosthetic valve infection & 4 & 6 & 0.495 \\
\hline 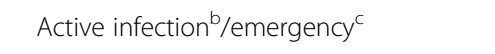 & $27 / 4$ & 29/ 4 & $0.555 />0.999$ \\
\hline \multicolumn{4}{|l|}{ Medications } \\
\hline ACEi/ARB & 8 & 8 & $>0.999$ \\
\hline$\beta$-blockers & 7 & 8 & 0.771 \\
\hline Calcium channel blockers & 3 & 4 & 0.690 \\
\hline Diuretics & 12 & 14 & 0.621 \\
\hline Antiplatelet drugs & 5 & 0 & 0.020 \\
\hline \multicolumn{4}{|l|}{ Operation } \\
\hline Aortic valve replacement & 11 & 7 & 0.274 \\
\hline Mitral valve replacement & 17 & 19 & 0.632 \\
\hline Double valve operation & 4 & 2 & 0.393 \\
\hline Tricuspid annuloplasty & 2 & 3 & 0.643 \\
\hline Valve + aorta & 1 & 4 & 0.164 \\
\hline
\end{tabular}

Values are mean \pm standard deviation, number of patients, or median (interquartile range). SCr serum creatinine, $M I$ myocardial infarction, $C O P D$ chronic obstructive lung disease, $A C E i$ angiotensin converting enzyme inhibitors, $A R B$ angiotensin receptor blockers, $C A B G$ coronary artery bypass graft; ${ }^{\text {CCleveland }}$ Clinic Foundation Acute Renal Failure Scoring System (minimum score =0; maximum score $=17$ ); bactive infection, patients exhibiting an active infection with a positive blood culture, leukocytosis $(>10,800 / \mu \mathrm{l})$, fever $\left(>38^{\circ} \mathrm{C}\right)$, or C-reactive protein $>8 \mathrm{mg} / \mathrm{l}$; 'emergency, patients undergoing emergency operation within $24 \mathrm{~h}$ after being diagnosed with infective endocarditis

bicarbonate group $(P=0.048)$ (Table 4$)$. The incidence rates of alkalemia $(20 \%$ vs. $11 \%, P=0.324)$, hypernatremia $(0 \%$ vs. $3 \%, P=0.314)$, and hypokalemia $(17 \%$ vs. $14 \%, P=0.743)$ during the five PODs were similar in both groups.

\section{Non-renal postoperative outcomes}

Changes in body temperature $(P=0.621)$, C-reactive protein level $(P=0.611)$, white blood cell count $(P=0.511)$, and percentage of neutrophils $(P=0.539)$ during the five PODs were similar in both groups (see Additional file 2 
Table 2 Incidence of postoperative acute kidney injury, serum creatinine level and glomerular filtration rate

\begin{tabular}{|c|c|c|c|}
\hline & Control group $(n=35)$ & Bicarbonate group $(n=35)$ & $P$ value \\
\hline \multicolumn{4}{|l|}{ Serum creatinine $(\mathrm{mg} / \mathrm{dl})^{*}$} \\
\hline before surgery & $0.90 \pm 0.36$ & $0.83 \pm 0.24$ & \multirow[t]{6}{*}{0.055} \\
\hline immediately after surgery & $0.83 \pm 0.36^{\dagger}$ & $0.73 \pm 0.22^{\dagger}$ & \\
\hline at $24 \mathrm{~h}$ after surgery & $0.99 \pm 0.35^{\dagger}$ & $1.01 \pm 0.41^{\dagger}$ & \\
\hline at $48 \mathrm{~h}$ after surgery & $0.94 \pm 0.38$ & $1.13 \pm 0.65^{\dagger}$ & \\
\hline at $72 \mathrm{~h}$ after surgery & $0.89 \pm 0.38$ & $1.08 \pm 0.70^{\dagger}$ & \\
\hline at $120 \mathrm{~h}$ after surgery & $0.84 \pm 0.32$ & $0.99 \pm 0.65$ & \\
\hline \multicolumn{4}{|c|}{ Glomerular filtration rate $\left(\mathrm{ml} / \mathrm{min} \text { per } 1.73 \mathrm{~m}^{2}\right)^{*}$} \\
\hline before surgery & $89.6 \pm 34.6$ & $94.1 \pm 36.9$ & \multirow[t]{6}{*}{0.073} \\
\hline immediately after surgery & $96.5 \pm 43.4^{\dagger}$ & $102.4 \pm 42.2$ & \\
\hline at $24 \mathrm{~h}$ after surgery & $79.3 \pm 35.1^{\dagger}$ & $79.6 \pm 39.3^{\dagger}$ & \\
\hline at $48 \mathrm{~h}$ after surgery & $85.7 \pm 40.5$ & $75.2 \pm 38.6^{\dagger}$ & \\
\hline at $72 \mathrm{~h}$ after surgery & $91.1 \pm 40.3$ & $81.2 \pm 40.0^{\dagger}$ & \\
\hline at $120 \mathrm{~h}$ after surgery & $94.7 \pm 36.8$ & $86.0 \pm 42.4$ & \\
\hline \multicolumn{4}{|l|}{ AKIN classification } \\
\hline None $(n)$ & $27(77 \%)$ & $25(71 \%)$ & \multirow[t]{4}{*}{0.863} \\
\hline Stage $1(n)$ & $6(17 \%)$ & $6(17 \%)$ & \\
\hline Stage $2(n)$ & $1(3 \%)$ & $2(6 \%)$ & \\
\hline Stage $3(n)$ & $1(3 \%)$ & $2(6 \%)$ & \\
\hline Any category & $8(23 \%)$ & $10(29 \%)$ & 0.584 \\
\hline
\end{tabular}

Values are mean \pm standard deviation or numbers (\%). Postoperative acute kidney injury (AKI) was diagnosed according to the Acute Kidney Injury Network (AKIN) classification. ${ }^{*} P$ value demonstrates the value for the group $\times$ time interaction in the linear mixed model; ${ }^{\dagger} P<0.05$ vs. baseline value

for more detail). The incidence of a composite of morbidity endpoints $(P=0.621)$ and the ICU and hospital length of stay were also similar in the two groups. Two patients in the control group died during their hospital stay because of cerebral hemorrhage, whereas no mortality occurred in the bicarbonate group (Table 5).

\section{Discussion}

In this prospective, randomized, placebo-controlled trial we did not observe any beneficial effects of perioperative bicarbonate administration on postoperative renal function in patients with IE undergoing cardiac surgery with $\mathrm{CPB}$. Sodium bicarbonate did not attenuate the peak postoperative $\mathrm{SCr}$ level nor reduce the incidence of AKI defined by the AKIN criteria. In fact, the postoperative increase in $\mathrm{SCr}$ above baseline was even greater in the bicarbonate group than in the control group.

Acute IE is a challenging disease that is associated with high morbidity and mortality. Although most patients with IE undergo medical treatment, more than $20 \%$ require surgery, and the number of surgical treatments has gradually increased as accumulating evidence supports the use of cardiac surgery to improve outcomes $[1,2]$. However, morbidity and mortality following cardiac surgery in patients with IE remain significant. AKI is one of the most common morbidities, with a rate of
20-60\% [6, 22]. Moreover, AKI clearly increases longterm postoperative mortality and cardiac event rates in patients with IE $[6,23]$, but definitive strategies to prevent AKI in this patient population have not been established.

The systemic inflammation and oxidative stress associated with septic conditions predispose patients with IE undergoing cardiac surgery to AKI [5]. Furthermore, prolonged use of nephrotoxic antibiotics preoperatively, and administration of contrast media shortly before cardiac surgery, adds to the risk of AKI by enhancing proinflammatory oxidative stress $[16,24]$. Sodium bicarbonate administration produces blood and urine alkalization and may slow pH-dependent Haber-Weiss free-radical production, thereby attenuating reactive oxygen speciesmediated tubular injury [11, 24, 25]. Sodium bicarbonate may also directly scavenge other reactive species [26]. Tubular alkalosis achieved by sodium bicarbonate has been demonstrated to mitigate the conversion of hemoglobin to methemoglobin, preventing tubular obstruction and tubular cell necrosis [10]. Accordingly, sodium bicarbonate administration has shown benefits in experimental models of ischemic [27], doxorubicin-induced [28], and contrastmedium-induced AKI [29]. However, several trials and meta-analyses investigating the renal effects of sodium bicarbonate in the context of cardiac surgery yielded 
Table 3 Intraoperative data

\begin{tabular}{|c|c|c|c|}
\hline & Control group $(n=35)$ & Bicarbonate group $(n=35)$ & $P$ value \\
\hline Operation time (minutes) & $227.9 \pm 67.0$ & $211.8 \pm 94.5$ & 0.412 \\
\hline Anesthesia time (minutes) & $270.7 \pm 78.0$ & $265.5 \pm 105.6$ & 0.815 \\
\hline Cardiopulmonary bypass time (minutes) & $118.7 \pm 51.8$ & $109.6 \pm 75.1$ & 0.554 \\
\hline Aortic cross-clamp time (minutes) & $87.3 \pm 43.3$ & $77.6 \pm 56.5$ & 0.424 \\
\hline \multicolumn{4}{|l|}{ Fluid balance } \\
\hline Crystalloid (ml) & $1000(775,1200)$ & $1000(600,1375)$ & 0.995 \\
\hline Colloid (ml) & $130(100,300)$ & $100(100,200)$ & 0.288 \\
\hline Urine output (ml) & $870(560,1240)$ & $1000(600,1250)$ & 0.526 \\
\hline Ultrafiltration during $\mathrm{CPB}(\mathrm{ml}) / n^{\mathrm{a}}$ & $2000(1250,2400) / 25$ & $1550(1300,2100) / 26$ & $0.216 / 0.788$ \\
\hline \multicolumn{4}{|l|}{ Transfusion } \\
\hline Amount of cell saver (ml) & $500.0(477.5,740.0)$ & $500.0(480.0,730.0)$ & 0.652 \\
\hline Amount of erythrocyte (unit) & $1(0,2)$ & $1(0,2)$ & 0.916 \\
\hline Patients transfused with erythrocyte & 21 & 21 & $>0.999$ \\
\hline Patients transfused with FFP & 18 & 17 & 0.811 \\
\hline Patients transfused with PLT & 12 & 4 & 0.023 \\
\hline \multicolumn{4}{|l|}{ Vasopressor/ Inotrope needs } \\
\hline Norepinephrine dose ( $\mathrm{gg} / \mathrm{kg} / \mathrm{min})$ & $0.03(0.01,0.04)$ & $0.02(0.01,0.05)$ & 0.317 \\
\hline Patients needed vasopressin & 16 & 14 & 0.629 \\
\hline Patients needed milrinone & 4 & 4 & $>0.999$ \\
\hline
\end{tabular}

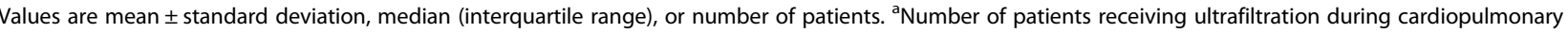
bypass (CPB). FFP fresh frozen plasma, PLT platelet

inconsistent results $[8,14,15,21]$. Based on the theoretical ability of sodium bicarbonate to reduce oxidative stress in renal tubular cells, we investigated whether perioperative sodium bicarbonate infusion would lessen renal injury in this patient population, an issue that has not been previously addressed.

Contrary to our expectation, sodium bicarbonate infusion did not demonstrate renoprotective effects in this study. The postoperative peak SCr level and incidence of AKI defined by the AKIN criteria were similar in both groups. Indeed, when AKI was diagnosed using the criteria that were applied in the first trial reporting renoprotective effects of sodium bicarbonate in cardiac surgery (increase in SCr $>0.5 \mathrm{mg} / \mathrm{dl}$ or $25 \%$ above baseline) [8], the incidence of AKI was significantly greater in the bicarbonate group than in the control group. Moreover, the increase in postoperative SCr levels above baseline was significantly greater in the bicarbonate group than in the control group.

These results imply that the effects of sodium bicarbonate on renal function may not just be neutral, but they may even be harmful in patients with IE undergoing cardiac surgery, which argues against the routine use of sodium bicarbonate. Notably, intraoperative platelet transfusion requirement was higher in the control group than in the bicarbonate group, which might be attributed to the fact that more patients received anti-platelet drugs
(5 vs. $0, P=0.020$ ) and had platelet counts below $150,000 / \mu$ l (11 vs. $3, P=0.017)$ in the control group. In addition, packed erythrocyte transfusion requirement during the $24 \mathrm{~h}$ postoperatively was also higher in the control group than in the bicarbonate group. Erythrocyte and platelet transfusions are associated with an increased risk of AKI and dialysis [30, 31]. Thus, the higher incidence of AKI in the bicarbonate group despite less transfusion further supports the possibly harmful impact of bicarbonate infusions.

In the context of cardiac surgery, previous findings demonstrate that the renoprotective effects of sodium bicarbonate were limited to low-risk patients [12, 32]. Furthermore, a recent trial of prophylactic sodium bicarbonate therapy to prevent AKI in high-risk patients was terminated early because of increased mortality in the bicarbonate group [15]. This difference according to the patient's risk is consistent with our results, as our patients had a high risk of AKI because of infection, severe inflammation, receipt of nephrotoxic antibiotics, and surgery-related injury. The likelihood of postoperative AKI is higher in patients with more risk factors [6], and a single treatment strategy might be insufficient to attenuate renal injury in patients with multiple risk factors. This might be the most cogent explanation for our results.

The inability of sodium bicarbonate to reduce AKI was discussed from the perspective of alkalemia and resultant 
Table 4 Postoperative input, output, and vasoconstrictor use

\begin{tabular}{|c|c|c|c|}
\hline & Control group $(n=35)$ & Bicarbonate group $(n=35)$ & $P$ value \\
\hline \multicolumn{4}{|l|}{ Crystalloid input (ml) } \\
\hline during postoperative $24 \mathrm{~h}$ & $2550(2000,3374)$ & $2250(1850,3170)$ & 0.226 \\
\hline during postoperative $48 \mathrm{~h}$ & $1950(1420,2565)$ & $1990(1065,2550)$ & 0.450 \\
\hline \multicolumn{4}{|l|}{ Colloid input (ml) } \\
\hline during postoperative $24 \mathrm{~h}$ & $340(100,500)$ & $280(0,420)$ & 0.157 \\
\hline during postoperative $48 \mathrm{~h}$ & $0(0,0)$ & $0(0,0)$ & 0.196 \\
\hline \multicolumn{4}{|l|}{ Urine output (ml) } \\
\hline during postoperative $24 \mathrm{~h}$ & $3225(2420,3610)$ & $2790(2205,3530)$ & 0.375 \\
\hline during postoperative $48 \mathrm{~h}$ & $2800(2190,3515)$ & $2490(1700,3915)$ & 0.597 \\
\hline \multicolumn{4}{|l|}{ Chest tube drainage (ml) } \\
\hline during postoperative $24 \mathrm{~h}$ & $230(150,523)$ & $200(144,311)$ & 0.372 \\
\hline during postoperative $48 \mathrm{~h}$ & $160(90,336)$ & $130(70,280)$ & 0.269 \\
\hline \multicolumn{4}{|l|}{ Erythrocyte (unit) transfusion } \\
\hline during postoperative $24 \mathrm{~h}(n)^{\mathrm{a}}$ & $0(0,1)(17)$ & $0(0,1)(9)$ & $0.076(0.048)$ \\
\hline during postoperative $48 \mathrm{~h}(n)^{\mathrm{a}}$ & $0(0,0)(4)$ & $0(0,0)(5)$ & $0.724(0.721)$ \\
\hline \multicolumn{4}{|l|}{ Norepinephrine ( $\mu \mathrm{g} / \mathrm{kg} / \mathrm{min})$} \\
\hline during postoperative $24 \mathrm{~h}$ & $0.02(0.01,0.03)$ & $0.02(0.01,0.05)$ & 0.860 \\
\hline during postoperative $48 \mathrm{~h}$ & $0.02(0.01,0.02)$ & $0.04(0.04,0.08)$ & 0.200 \\
\hline \multicolumn{4}{|l|}{ Patients needed milrinone $(n)$} \\
\hline during postoperative $24 \mathrm{~h}$ & 9 & 6 & 0.382 \\
\hline during postoperative $48 \mathrm{~h}$ & 3 & 4 & 0.690 \\
\hline
\end{tabular}

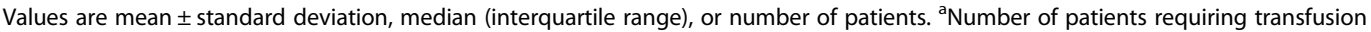

physiologic changes in previous studies [13-15]. Alkalemia can lead to impaired tissue perfusion [33, 34] and oxygen delivery [35], and to increased cell death and apoptosis associated with superoxide formation [36]. Most patients enrolled in our study had active inflammation and received prolonged treatment with multiple nephrotoxic antibiotics, which would aggravate renal injury associated with increased renal vascular resistance and tubular cell impairment $[5,37,38]$. During active systemic inflammation, increased renal vascular resistance (uncoupled from decreased systemic vascular resistance) may diminish renal perfusion, thereby causing ischemia [5, 38]. Indeed, multiple areas of renal infarction were observed in an animal model of IE, suggesting hypoperfusion-induced ischemia [39]. Nephrotoxic antibiotics have also been demonstrated to reduce renal blood flow by increasing renal vascular resistance rather than by lowering perfusion pressure [40]. Alkalosis following

Table 5 Postoperative outcomes

\begin{tabular}{|c|c|c|c|}
\hline & Control group $(n=35)$ & Bicarbonate group $(n=35)$ & $P$ value \\
\hline Composite of morbidity endpoints & $14(40 \%)$ & $12(34 \%)$ & 0.621 \\
\hline Permanent stroke & $3(9 \%)$ & 0 & 0.077 \\
\hline Hemostatic reoperation & $5(14 \%)$ & $4(11 \%)$ & 0.721 \\
\hline Acute kidney injury & $8(23 \%)$ & $10(29 \%)$ & 0.584 \\
\hline Ventilator care $>48 \mathrm{~h}$ & $2(6 \%)$ & $2(6 \%)$ & $>0.999$ \\
\hline Deep sternal wound infection & $1(3 \%)$ & $1(3 \%)$ & $>0.999$ \\
\hline In-hospital mortality & $2(6 \%)$ & 0 & 0.151 \\
\hline Duration of ventilator care $(h)$ & $17(13,20)$ & $15(10,22)]$ & 0.448 \\
\hline Duration of intensive care unit stay (days) & $2(2,3)$ & $2(1,3)$ & 0.361 \\
\hline Duration of hospital stay (days) & $28(17,35)$ & $26(15,32)$ & 0.350 \\
\hline
\end{tabular}

Values are number of patients (\%) or median (interquartile range) 
sodium bicarbonate infusion could further increase renal vascular resistance [34] and exacerbate renal tubular injury by producing intracellular acidosis. A rapid influx of $\mathrm{CO}_{2}$ following sodium bicarbonate infusion could worsen intracellular acidosis [41], accelerating the influx of sodium and calcium, and causing cell swelling and renal tubule dysfunction [42].

There has been a paucity of randomized, controlled trials in patients with IE undergoing cardiac surgery. This may be at least partly because these patients are often unstable or require urgent surgery, leading to a preponderance of observational studies. Thus, the primary strength of this study is that it is the first to address the renoprotective efficacy of sodium bicarbonate through randomization, solely in patients with IE undergoing cardiac surgery, although the sample size was not sufficient to compare the incidence of AKI, which is the most clinically relevant index.

The limitations of this study are as follows. First, we did not directly measure urine $\mathrm{pH}$ to confirm urinary alkalization by IV sodium bicarbonate administration. However, both plasma and urinary alkalization were achieved in previous studies using similar doses and durations of sodium bicarbonate infusion $[8,15,21]$. Second, we can only speculate on the reasons for the lack of beneficial effect of sodium bicarbonate in this study, because no mechanistic investigations were conducted. Third, we used balanced 130/0.4 hydroxyethyl starch solution (Volulyte) for volume replacement, upon which concerns have been raised regarding its nephrotoxicity in patients with sepsis. However, its influence on renal function is far more controversial when used in the operating theatre. Indeed, there is solid evidence favoring its use in the presence of overt volume loss [43-45]. Furthermore, the median volume used in this study did not exceed $500 \mathrm{ml}$ in either group throughout the perioperative $24 \mathrm{~h}$, without any intergroup difference. Thus, its influence on the observed results should be negligible.

\section{Conclusions}

Perioperative sodium bicarbonate administration did not improve postoperative renal function or other outcomes in patients with IE undergoing cardiac surgery. Rather, it was associated with potentially harmful renal effects, as demonstrated by a greater postoperative increase in $\mathrm{SCr}$ above baseline, compared to control. Further research on renoprotective strategies in patients with IE is warranted.

\section{Additional files}

Additional file 1: Perioperative hemodynamic variables. Changes in heart rate, mean blood pressure, mean pulmonary arterial pressure, and central venous pressure during the perioperative period. (PDF $48 \mathrm{~kb}$ )
Additional file 2: Perioperative body temperature and laboratory findings. Change in blood temperature, C-reactive protein, white blood cell count, and neutrophils during the perioperative period. (PDF $115 \mathrm{~kb}$ )

\section{Abbreviations \\ AKI: acute kidney injury; AKIN: Acute Kidney Injury Network; Cl: cardiac index; CPB: cardiopulmonary bypass; CVP: central venous pressure; eGFR: estimated glomerular filtration rate; HR: heart rate; ICU: intensive care unit; IE: infective endocarditis; IV: intravenous; MAP: mean arterial pressure; MPAP: mean pulmonary arterial pressure; POD: postoperative day; SCr: serum creatinine; SD: standard deviation}

\section{Acknowledgements}

Not applicable.

Funding

Nothing to declare.

Availability of data and materials

The datasets used and/or analyzed during the current study are available from the corresponding author on reasonable request.

Authors' contributions

JSC and YLK conceived the study design, collected, analyzed and interpreted the data, performed the statistical analysis, and wrote the manuscript. JKS contributed substantially to interpreting the data and critically revised the manuscript for important intellectual content. SS and SK contributed substantially to collecting and interpreting the data. HG contributed substantially to collecting the data and performed the statistical analysis. All authors read and approved the final manuscript.

\section{Competing interests}

The authors declare that they have no competing interests.

\section{Consent for publication}

Not applicable.

\section{Ethics approval and consent to participate}

The study protocol was approved by the Institutional Review Board and Hospital Research Ethics Committee of Severance Hospital at Yonsei University College of Medicine (\#4-2013-0376). All patients provided written informed consent.

\section{Author details}

${ }^{1}$ Department of Anesthesiology and Pain Medicine, Yonsei Cardiovascular Hospital, Yonsei University College of Medicine, 50 Yonsei-ro, Seodaemun-gu, Seoul 120-752, Republic of Korea. ${ }^{2}$ Anesthesia and Pain Research Institute, Yonsei University College of Medicine, Seoul, Republic of Korea. ${ }^{3}$ Department of Anesthesiology and Pain Medicine, National Health Insurance Corporation Ilsan Hospital, Gyeonggi-do, Republic of Korea.

Received: 11 October 2016 Accepted: 12 December 2016 Published online: 05 January 2017

\section{References}

1. Lalani T, Cabell CH, Benjamin DK, Lasca O, Naber C, Fowler Jr VG, Corey GR, Chu VH, Fenely M, Pachirat O, et al. Analysis of the impact of early surgery on in-hospital mortality of native valve endocarditis: use of propensity score and instrumental variable methods to adjust for treatment-selection bias. Circulation. 2010;121(8):1005-13.

2. Kang DH, Kim YJ, Kim SH, Sun BJ, Kim DH, Yun SC, Song JM, Choo SJ, Chung $\mathrm{CH}$, Song JK, et al. Early surgery versus conventional treatment for infective endocarditis. N Engl J Med. 2012;366(26):2466-73.

3. Mao H, Katz N, Ariyanon W, Blanca-Martos L, Adybelli Z, Giuliani A, Danesi TH, Kim JC, Nayak A, Neri M, et al. Cardiac surgery-associated acute kidney injury. Cardiorenal Med. 2013;3(3):178-99.

4. Kinsey GR, Li L, Okusa MD. Inflammation in acute kidney injury. Nephron Exp Nephrol. 2008;109(4):e102-107. 
5. Benes J, Chvojka J, Sykora R, Radej J, Krouzecky A, Novak I, Matejovic M. Searching for mechanisms that matter in early septic acute kidney injury: an experimental study. Crit Care. 2011;15(5):R256.

6. Legrand M, Pirracchio R, Rosa A, Petersen ML, Van der Laan M, Fabiani JN Fernandez-gerlinger MP, Podglajen I, Safran D, Cholley B, et al. Incidence, risk factors and prediction of post-operative acute kidney injury following cardiac surgery for active infective endocarditis: an observational study. Crit Care. 2013;17(5):R220.

7. Alonso-Valle H, Farinas-Alvarez C, Garcia-Palomo JD, Bernal JM, Martin-Duran R, Gutierrez Diez JF, Revuelta JM, Farinas MC. Clinical course and predictors of death in prosthetic valve endocarditis over a 20-year period. J Thorac Cardiovasc Surg. 2010;139(4):887-93.

8. Haase M, Haase-Fielitz A, Bellomo R, Devarajan P, Story D, Matalanis G, Reade MC, Bagshaw SM, Seevanayagam N, Seevanayagam S, et al. Sodium bicarbonate to prevent increases in serum creatinine after cardiac surgery: a pilot double-blind, randomized controlled trial. Crit Care Med. 2009;37(1):39-47.

9. Haase M, Haase-Fielitz A, Bellomo R. Cardiopulmonary bypass, hemolysis, free iron, acute kidney injury and the impact of bicarbonate. Contrib Nephrol. 2010;165:28-32.

10. Schneider AG, Bellomo R, Reade M, Peck L, Young H, Eastwood GM, Garcia M, Moore E, Harley N. Safety evaluation of a trial of lipocalin-directed sodium bicarbonate infusion for renal protection in at-risk critically ill patients. Crit Care Resusc. 2013;15(2):126-33.

11. Merten GJ, Burgess WP, Gray LV, Holleman JH, Roush TS, Kowalchuk GJ, Bersin RM, Van Moore A. Simonton 3rd CA, Rittase RA, et al. Prevention of contrast-induced nephropathy with sodium bicarbonate: a randomized controlled trial. JAMA. 2004;291(19):2328-34.

12. Wetz AJ, Brauer A, Quintel M, Heise D. Does sodium bicarbonate infusion really have no effect on the incidence of acute kidney injury after cardiac surgery? A prospective observational trial. Crit Care. 2015;19:183.

13. Tian ML, Hu Y, Yuan J, Zha Y. Efficacy and safety of perioperative sodium bicarbonate therapy for cardiac surgery-associated acute kidney injury: a meta-analysis. J Cardiovasc Pharmacol. 2015;65(2):130-6.

14. Tie HT, Luo MZ, Luo MJ, Zhang M, Wu QC, Wan JY. Sodium bicarbonate in the prevention of cardiac surgery-associated acute kidney injury: a systematic review and meta-analysis. Crit Care. 2014;18(5):517.

15. Haase M, Haase-Fielitz A, Plass M, Kuppe H, Hetzer R, Hannon C, Murray PT, Bailey MJ, Bellomo R, Bagshaw SM. Prophylactic perioperative sodium bicarbonate to prevent acute kidney injury following open heart surgery: a multicenter double-blinded randomized controlled trial. PLoS Med. 2013; 10(4):e1001426.

16. Bamgbola O. Review of vancomycin-induced renal toxicity: an update. Ther Adv Endocrinol Metab. 2016;7(3):136-47.

17. Li JS, Sexton DJ, Mick N, Nettles R, Fowler Jr VG, Ryan T, Bashore T, Corey GR. Proposed modifications to the Duke criteria for the diagnosis of infective endocarditis. Clin Infect Dis. 2000;30(4):633-8.

18. Yoo YC, Shim JK, Song Y, Yang SY, Kwak YL. Anesthetics influence the incidence of acute kidney injury following valvular heart surgery. Kidney Int. 2014;86(2):414-22.

19. Mehta RL, Kellum JA, Shah SV, Molitoris BA, Ronco C, Warnock DG, Levin A. Acute Kidney Injury N: Acute Kidney Injury Network: report of an initiative to improve outcomes in acute kidney injury. Crit Care. 2007;11(2):R31.

20. Thakar CV, Arrigain S, Worley S, Yared JP, Paganini EP. A clinical score to predict acute renal failure after cardiac surgery. J Am Soc Nephrol. 2005; 16(1):162-8.

21. McGuinness SP, Parke RL, Bellomo R, Van Haren FM, Bailey M. Sodium bicarbonate infusion to reduce cardiac surgery-associated acute kidney injury: a phase II multicenter double-blind randomized controlled trial. Crit Care Med. 2013:41(7):1599-607.

22. Pang PY, Sin YK, Lim CH, Tan TE, Lim SL, Chao VT, Chua YL. Surgical management of infective endocarditis: an analysis of early and late outcomes. Eur J Cardiothorac Surg. 2015;47(5):826-32.

23. Tamura $\mathrm{K}$, Arai H, Yoshizaki T. Long-term outcome of active infective endocarditis with renal insufficiency in cardiac surgery. Ann Thorac Cardiovasc Surg. 2012;18(3):216-21.

24. Halliwell B, Gutteridge JM. Role of free radicals and catalytic metal ions in human disease: an overview. Methods Enzymol. 1990;186:1-85.

25. Brar SS, Shen AY, Jorgensen MB, Kotlewski A, Aharonian VJ, Desai N, Ree M, Shah Al, Burchette RJ. Sodium bicarbonate vs sodium chloride for the prevention of contrast medium-induced nephropathy in patients undergoing coronary angiography: a randomized trial. JAMA. 2008;300(9):1038-46.
26. Caulfield JL, Singh SP, Wishnok JS, Deen WM, Tannenbaum SR. Bicarbonate inhibits N-nitrosation in oxygenated nitric oxide solutions. J Biol Chem. 1996;271(42):25859-63.

27. Atkins JL. Effect of sodium bicarbonate preloading on ischemic renal failure. Nephron. 1986;44(1):70-4.

28. Baroni EA, Costa RS, Volpini R, Coimbra TM. Sodium bicarbonate treatment reduces renal injury, renal production of transforming growth factor-beta, and urinary transforming growth factor-beta excretion in rats with doxorubicin-induced nephropathy. Am J Kidney Dis. 1999;34(2):328-37.

29. Vattimo M, dos Santos JG. Protective effect of sodium bicarbonate on radiological contrast medium-induced nephropathy in rats. Rev Esc Enferm USP. 2013;47(3):722-7.

30. Bojan M, Vicca S, Boulat C, Gioanni S, Pouard P. Aprotinin, transfusions, and kidney injury in neonates and infants undergoing cardiac surgery. $\mathrm{Br} J$ Anaesth. 2012;108(5):830-7.

31. Kashani K, Steuernagle JH, Akhoundi A, Alsara A, Hanson AC, Kor DJ. Vascular Surgery Kidney Injury Predictive Score: a historical cohort study. J Cardiothorac Vasc Anesth. 2015;29(6):1588-95.

32. Bailey M, McGuinness S, Haase M, Haase-Fielitz A, Parke R, Hodgson CL, Forbes A, Bagshaw SM, Bellomo R. Sodium bicarbonate and renal function after cardiac surgery: a prospectively planned individual patient metaanalysis. Anesthesiology. 2015;122(2):294-306.

33. Adrogue HJ. Mixed acid-base disturbances. J Nephrol. 2006;19 Suppl 9:S97-103.

34. Baretella O, Xu A, Vanhoutte PM. Acidosis prevents and alkalosis augments endothelium-dependent contractions in mouse arteries. Pflugers Arch. 2014; 466(2):295-305.

35. Kilmartin JV. Interaction of haemoglobin with protons, CO2 and 2,3diphosphoglycerate. Br Med Bull. 1976;32(3):209-12.

36. Hougardy JM, De Backer D. Sodium bicarbonate to prevent cardiac surgeryassociated kidney injury: the end of a dream? Crit Care. 2012;16(6):186.

37. Lopez-Novoa JM, Quiros Y, Vicente L, Morales Al, Lopez-Hernandez FJ. New insights into the mechanism of aminoglycoside nephrotoxicity: an integrative point of view. Kidney Int. 2011;79(1):33-45.

38. Chvojka J, Sykora R, Krouzecky A, Radej J, Varnerova V, Karvunidis T, Hes O, Novak I, Radermacher P, Matejovic M. Renal haemodynamic, microcirculatory, metabolic and histopathological responses to peritonitis-induced septic shock in pigs. Crit Care. 2008:12(6):R164.

39. Salgado-Pabon W, Breshears L, Spaulding AR, Merriman JA, Stach CS, Horswill AR, Peterson ML, Schlievert PM: Superantigens are critical for Staphylococcus aureus Infective endocarditis, sepsis, and acute kidney injury. MBio. 2013;4(4):e00494-13.

40. Klotman PE, Yarger WE. Reduction of renal blood flow and proximal bicarbonate reabsorption in rats by gentamicin. Kidney Int. 1983;24(5):638-43.

41. Levraut J, Giunti C, Ciebiera JP, de Sousa G, Ramhani R, Payan P, Grimaud D. Initial effect of sodium bicarbonate on intracellular $\mathrm{pH}$ depends on the extracellular nonbicarbonate buffering capacity. Crit Care Med. 2001;29(5):1033-9.

42. Velissaris D, Karamouzos V, Ktenopoulos N, Pierrakos C, Karanikolas M. The use of sodium bicarbonate in the treatment of acidosis in sepsis: a literature update on a long term debate. Crit Care Res Pract. 2015;2015:605830.

43. Annane D, Siami S, Jaber S, Martin C, Elatrous S, Declere AD, Preiser JC, Outin $\mathrm{H}$, Troche G, Charpentier C, et al. Effects of fluid resuscitation with colloids vs crystalloids on mortality in critically ill patients presenting with hypovolemic shock: the CRISTAL randomized trial. JAMA. 2013:310(17):1809-17.

44. James MF, Michell WL, Joubert IA, Nicol AJ, Navsaria PH, Gillespie RS. Resuscitation with hydroxyethyl starch improves renal function and lactate clearance in penetrating trauma in a randomized controlled study: the FIRST trial (Fluids in Resuscitation of Severe Trauma). Br J Anaesth. 2011; 107(5):693-702.

45. Umegaki T, Uba T, Sumi C, Sakamoto $S$, Jomura S, Hirota K, Shingu K. Impact of hydroxyethyl starch 70/0.5 on acute kidney injury after gastroenterological surgery. Korean J Anesthesiol. 2016:69(5):460-7. 